\title{
Ethnobotanical Study of Medicinal Plants by Shenasha People Used to Treat Human Ailment in Dibati District, Northwest Ethiopia
}

\author{
Abesh Birhanu Morka ${ }^{1, \text { * }}$, Tena Regassa Duressa ${ }^{2, *}$ \\ ${ }^{1}$ Ethiopia Biodiversity Institution, Mettu Biodiversity Center, Forest and Range Land Plant Biodiversity Case Team, Mettu, Ethiopia \\ ${ }^{2}$ Department of Biology, Faculty of Natural and Computational Sciences, Wollega University, Nekemete, Ethiopia
}

Email address:

birhanuabesh12@gmail.com (A. B. Morka), tenaregasa@gmail.com (T. R. Duressa)

${ }^{*}$ Corresponding author

To cite this article:

Abesh Birhanu Morka, Tena Regassa Duressa. Ethnobotanical Study of Medicinal Plants by Shenasha People Used to Treat Human Ailment in Dibati District, Northwest Ethiopia. American Journal of Environmental and Resource Economics. Vol. 6, No. 3, 2021 , pp. 91-102. doi: $10.11648 /$ j.ajere.20210603.13

Received: July 3, 2021; Accepted: July 26, 2021; Published: September 7, 2021

\begin{abstract}
Background: In all part of the world traditional medicinal plant practices formed the basis of health cares for human being before the advent of modern medicine. In the Ethiopia people use traditional medicine for treatment of human ailment. Like other communities in Ethiopia, shenasha people are use traditional medicinal plant in Dibati District, Benshangule gumuze Region, Ethiopia. The objective of the study was to document traditional knowledge on medicinal plants in Dibati district northwest. Methods: The main data collection tools were semi structured interviews, discussions, and observation focused group discussion and various ranking and comparison methods were employed. Information was collected from a sample of 99 informants ( 77 males and 22 Females) included 20 (male 16 female 4 ) key informants are identified by the help of kebele administration. Results: Among the study of analysis 48 medicinal plant species with 46 genera and 28 families were recorded. In terms of this the Most of the species (36) were collected from the wild while 12 were collected from home garden were collected. Among the most widely used method of preparation was crashed (33.33\%), Pounding (18.75\%), of the different medicinal plant parts. Conclusion: In the study area possesses diverse natural vegetation and the environment under serious threated by mainly agricultural expansion, firewood collection, population pressure, overgrazing, urbanization, household tool construction, charcoal production and medicinal purpose. Awareness rising on the use and management systems, sustainable utilization of medicinal plants and their in-situ and ex-situ conservation and establishment of forest protected areas should be recommended.
\end{abstract}

Keywords: Medicinal Plant, Dibati Woreda, Informant, Shinasha People, Indigenes Knowledge, Ethnobotanical

\section{Introduction}

In all part of the world traditional medicinal plant practices formed the basis of health cares for both human being and animal before the advent of modern medicine. In the Ethiopia people have been using traditional medicine to treat both human and animal disease for generations. Traditional medicine is still wildly practices in rural area where modern medicine and services available [27]. Many of today's wonderful drugs were initially discovered through the study of traditional medicine [27]. Availability of medicinal plant has been affected by a dramatic decrease of native vegetation due to agricultural explanation, deforestation, fire, and overgrazing drought, tread of charcoal, firewood, introduction of alien invasive species and urban associated development. Medicinal plants obtained from wild habitats are found in different natural ecosystems of the forests, grasslands, woodlands, wetlands, in field margins and garden fences, as weeds and in many other microhabitats from where they are harvested when the need arise. There are many medicinal plants of Ethiopia that have good properties for land rehabilitation and erosion control Maintain health through traditional medicine in general and utilization of medicinal plant in particular is almost as old as the history of 
man kinds [9]. This is true in Ethiopia $80 \%$ of the population still relies on the plant to prevent and cure various health problem [15]. The current plant use trend in Dibati district shows that the environment is facing problems of resource depletion and loss of indigenous knowledge like other areas of the country. Thus, intensive ethnobotanical research plays a vital role to draw information on plants and related indigenous knowledge for conservation and sustainable utilization. Like many other parts of the country, there is no such ethnomedicinal research and documentation carried out in Dibati District, Metekele Zone, Northwest and Benshangul Gumuz Region. Dibati district is one of our research areas which are a very high amount of Shinasha people lives. In this woreda there is no any research which is done on the use of medicinal plants to treat human ailment by the Shinasha people's practices.

\section{Methods}

\subsection{Description of the Study Area}

The Benishangul Gumuz Regional State (BGRS) was established in 1994 as one of the nine regional states of Ethiopia. The BGRS borders the Republic of Sudan in the west, Amhara region in the North, Oromiya in the South east and Gambella region in the South. Administratively, it is divided in to 3 zones (Metekele, Assosa, and Kemashi) that are divided in to 19 Woreda, and one special Woreda. Metekel Zone is divided into 7 Woreda out of which Dibatie Woreda, the study area is located North 100 55'-110 90' latitude North and 300 12'-300 36' longitude East.(Source BGRS, 2008).
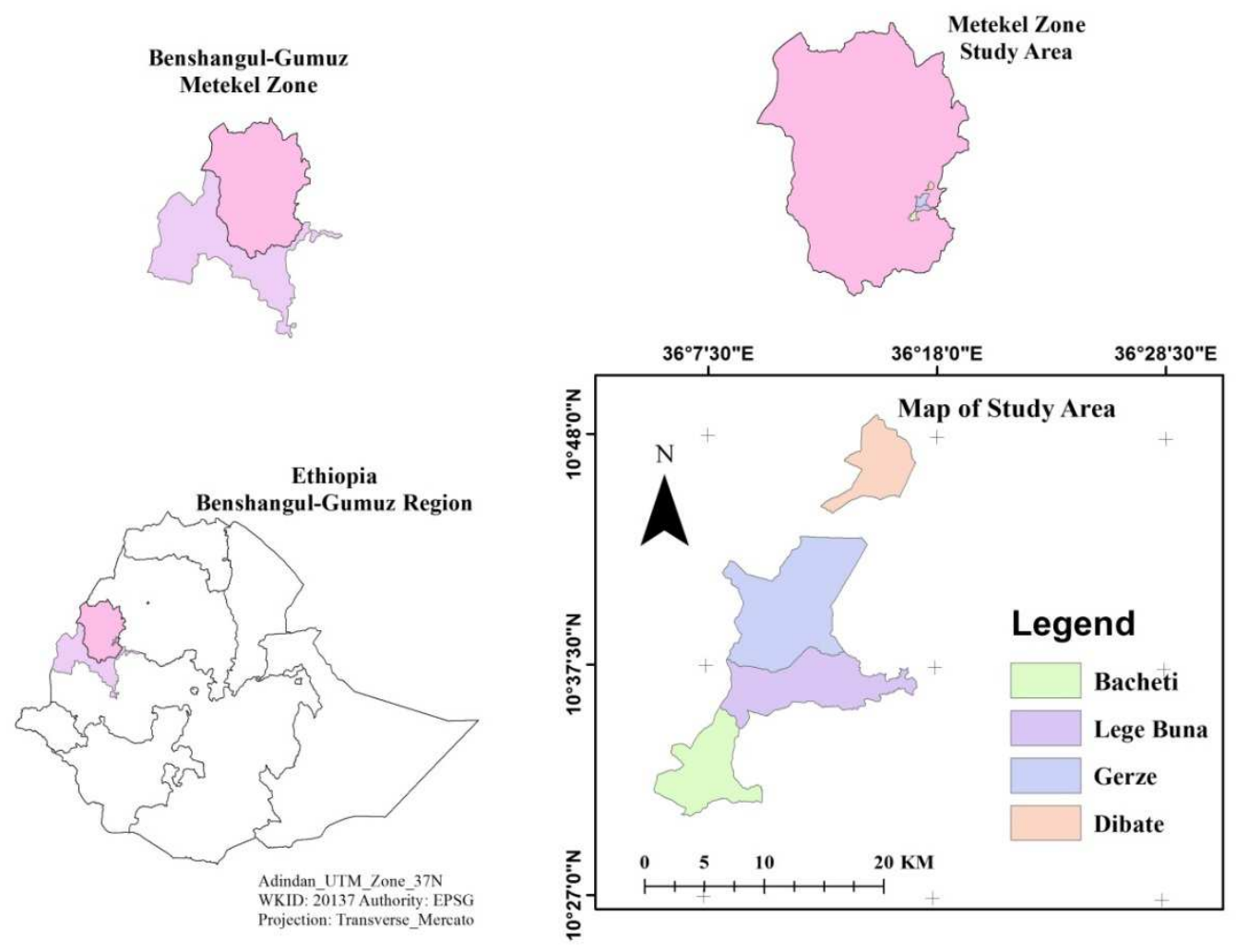

Figure 1. Map of the study area.

\subsection{Reconnaissance Survey and Selection of Study Sites}

Dibati Woreda has a total of 29 kebeles. Out of these, 5 kebeles was selected those are Modorem, Gerze, Zegehe, Legbuna, and Bechati due to the have high amount of shinasha peoples found in kebele. Additional to that they have larger vegetation cover and presence of key informants, different altitudinal ranges are selects for ethnobotanical data collection. The traditional healer, used as key informants, was identified by with the assistance of local authorities, elders and knowledgeable persons.

\subsection{Informant Selection}

Information regarding to each peasant association leaders the total household of Shenasha people in the study area of five kebele from the age of twenty and above is $(\mathrm{N})$ is male 651 female 141 total 792 . To obtain total sample size from the total targeted household, the researcher was use the usual known formula [30] that was calculated as follows:

$$
\mathrm{n}=\frac{N}{1+N(e)^{2}}
$$

Where $\mathrm{n}$ is sample size of the study area

$\mathrm{N}$ is targeted population size (total population of five kebele in study area.)

$\mathrm{e}:$ is the level of precision or sampling error $=(0.05)$

For the above formula, 


$$
\mathrm{n}=\frac{792}{1+792(0.05)^{2}}=99
$$

A total 99 informants five to seven individuals from each study kebele from the age of twenty and above were included. From the five studies kebele twenty key informants were purposively selected based on recommendations from local authorities (kebele administrators and local guides) peasant association leaders and other members of the local communities.

Plant specimen collection and identification

At the end of the interview, the reported medicinal plants were collected from natural vegetation and home garden. Sample specimens of the plants cited for their medicinal use was collected, numbered, pressed and dried for identification. Plant identification was performed both in the field, and at the National Herbarium of AAU. Preliminary identification was done in the field and reconfirmed at the National Herbarium. Identification of other plant specimens with my advisor Dr. Tena Regass and Wollega University herbarium workers was done in November 2017, using the Flora of Ethiopia and Eritrea and also by comparison with authenticated specimens.

\subsection{Ethnobotanical Data Collection}

Ethnobotanical data was collected between Octobers to November, 2017 on three field trips. The data was collected based on prepared questionnaires, semi-structured interviewees, observation, focus group discussion, and guided field walks with informants were employed to obtain indigenous knowledge of the local community of shinasha people. The study was carried out by interview in there habitants in different village. The informants include the various data sets such as local names, disease treated, parts of the plant used, and method of preparation dose and rote of application was obtained from local people through individual interviews. A list of question was prepared that covers the discussion with the informants in particular orders. All of the interviews were held in Amharic and Shinasha language of the local people. The place and time for discussion were set based on the interest of the informants. [7].

\subsection{Ethnobotanical Data Analysis}

The Ethnobotanical data collected was analyzed following survey and analytical tools for ethnobotanical methods which are Informant's preference ranking, descriptive statistic (Microsoft excel spreadsheets soft wore), Direct matrix ranking and paired comparisons conducted following) $[19,7$, 22]. Were computed to assess the degree of effectiveness of certain medicinal plants against human. Additional to that the use value (UV), a quantitative method that demonstrates the relative importance of species known locally [17]. was calculated using the following formula. $U V=\Sigma U / n$ where: $\mathrm{UV}=$ use value of a species; $\mathrm{U}=$ number of citations per species; $\mathrm{n}=$ number of informants.

Fidelity level index quantify the importance of a given species for a particular purpose in a given cultural group $[12,7]$.
The formula for FL is given as FL\% = Ip / Iu X 100, where Ip the number of informants who independently indicated the use of a species for the same major ailments and Iu the total number of informants who mentioned the plant for any major ailment [12].

Informant consensus factor (ICF) was calculated for categories of ailments to identify the agreements of the informants on the reported cures using the formula used by $[17,19]$. ICF was calculated as follows: number of use citations for each ailment (nur) minus the number of species used (nt) for that ailment, divided by the number of use citations for each ailment minus one. ICF $=$ nur_nt $/$ nur_1 where: ICF: Informant consensus Factor, Nur: number of use citation Nt: number of species used.

\section{Results and Discussion}

\subsection{Medicinal Plant Knowledge Among Informants}

In study area comparison of educational status, noneducated informants handled much knowledge of traditional medicine whereas educated informants had low knowledge of traditional medicine, which is an indicative of impact of modern education. Similar findings were reported by $[28,26$, 14, and 15].

Regarding to sex male are more knowlegeble medicinal plants than famales because of cultural influence and they can done more home activity. Similar results were reported by $[14,24]$.

Medicinal plants used to treat human ailments in the Dibati Woreda

The 48 of ethnomedicinally important plant species that are used to treat 57 human ailments recorded in five kebeles of Dibati woreda. These plants belong to 46 genera and 28 families. Family Fabaceae contributed 7 species, Astraeceae 3 species, Combrebitaceae 3 species, Euphorbiaceae Bignoniacea species, Amaranthaceae, Rubianceae, Alliaceacae, Cucuribitaceae, Olaceanceae, Lamianceaea, Polygonaceae, Ranunculaceae, Rutaceae and Solanaceae comprises 2 species in each, and represented by 2 species each and the rest 15 families comprises 1 species each. Some of the medicinal plants recorded are also used as remedies in other parts of Ethiopia. [11], documented 30 plant species, [20], 78 species and 12 plant species are mentioned [13].

The dominance of family Fabacaceae for the treatment of human diseases was reported in the work of $[8,3]$, and others [20]. This might be due to their weedy nature of the family Fabaceae and take advantages of disturbance.

\subsection{Major Human Ailments and Plant Species Used by Local People in the District}

Though more than 57 different diseases of humans were recorded as human health problem that are treated by 48 plant species, one species can treat a single disease or a number of diseases. The practitioners of the area commonly diagnose each health problem by an interview and visual inspection of the patient. These shows large numbers of 
diseases have got solution by traditional medicine in Dibati Woreda compared to different investigations in Ethiopia. For example, [14] reported 135 plant species that used to treat 65 aliments of humans and [24] reported 80 plant species that used to treat 49 aliments of humans.

According to the informants the largest number of species was used to treat snake biting, which is treated with 11 species. This disease is common in the area because most people engage in living the farmland as a result their men are susceptible to the snake biting; the next is eye vile is treated by 9 species. Amoebae, toothache, febrile illness and wound each disease are treated by 7 species and malaria, stomach ache common cold, retained placenta and abdominal pain each disease are treated by 5 species.

In addition to these, the practitioners were also visited more for diseases like gastritis, eye problem, homerriod, athlete foot and others.

\subsection{Habitat, Habit, Plant Part Used, Methods of \\ Preparation, Rout of Administration and Application of \\ Human Medicinal Plants in the Study Area}

From the medicinal plants that are used for human ailments, 36 species were collected from the wild vegetation and 12 species from home gardens. These indicated that the local people obtain medicinal plant species from wild vegetation than home gardens. This result agrees with $[10,8$, $28,26,14,24]$. This indicated that the practice of cultivation of medicine plants for their medicinal purpose in home gardens of most of the country is low although many plants are cultivated for other purposes, mainly for food. In a similar way people in the study area have less effort to cultivate medicinal plants in their home gardens rather go to the nearby or far places and harvest the plants.

\subsection{Habit Human Medicinal Plants}

In the study area there are many habits of medicinal plant those are herb, shrub, tree and climber. The result shows that analysis of growth forms of medicinal plants revealed that herbs constitute the largest category $19(39.58 \%)$ followed by tree $11(22.92 \%), 12(25.00 \%)$ shrub and $6(12.50 \%)$ Climbers were recorded. Some researchers previously studies $[5-10,4,13,25,21,14,24,6]$.

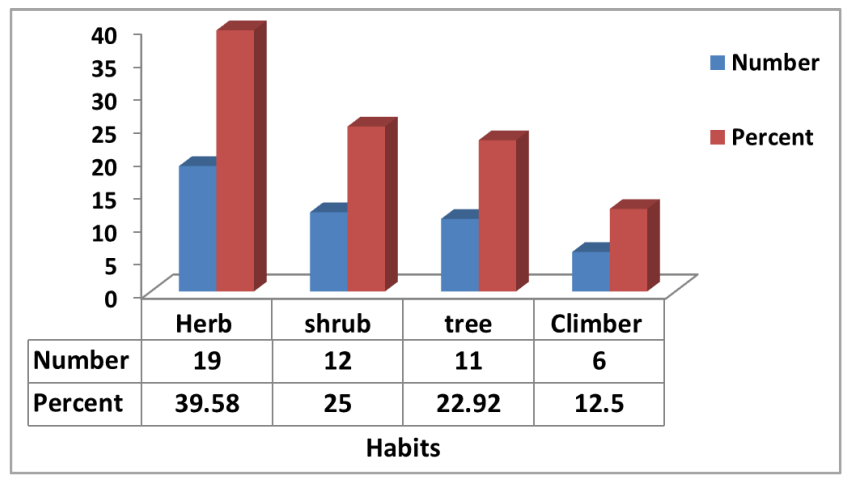

Figure 2. Habit of medicinal plants for human in the Dibati woreda.

\subsection{Plant Part Used to Treat Human Ailments}

From the total plant parts used for remedy preparation the leaves and the roots were the most commonly used plant parts in the preparation of remedies. The most widely used plant part for the preparations of remedy were leaves, which accounted for 10 (20.85\%) followed by roots $8(16.66 \%)$, seed $6(12.50 \%)$ break 4 $(8.33 \%)$ bulb $4(8.33)$ and others. The most part were leafe because of the avalibility of faild collection, ease to preparation and the avialibilty of medicinal content. This result agrees with following researcher $[5,10,25,8,4,13,21,14,24,6]$.

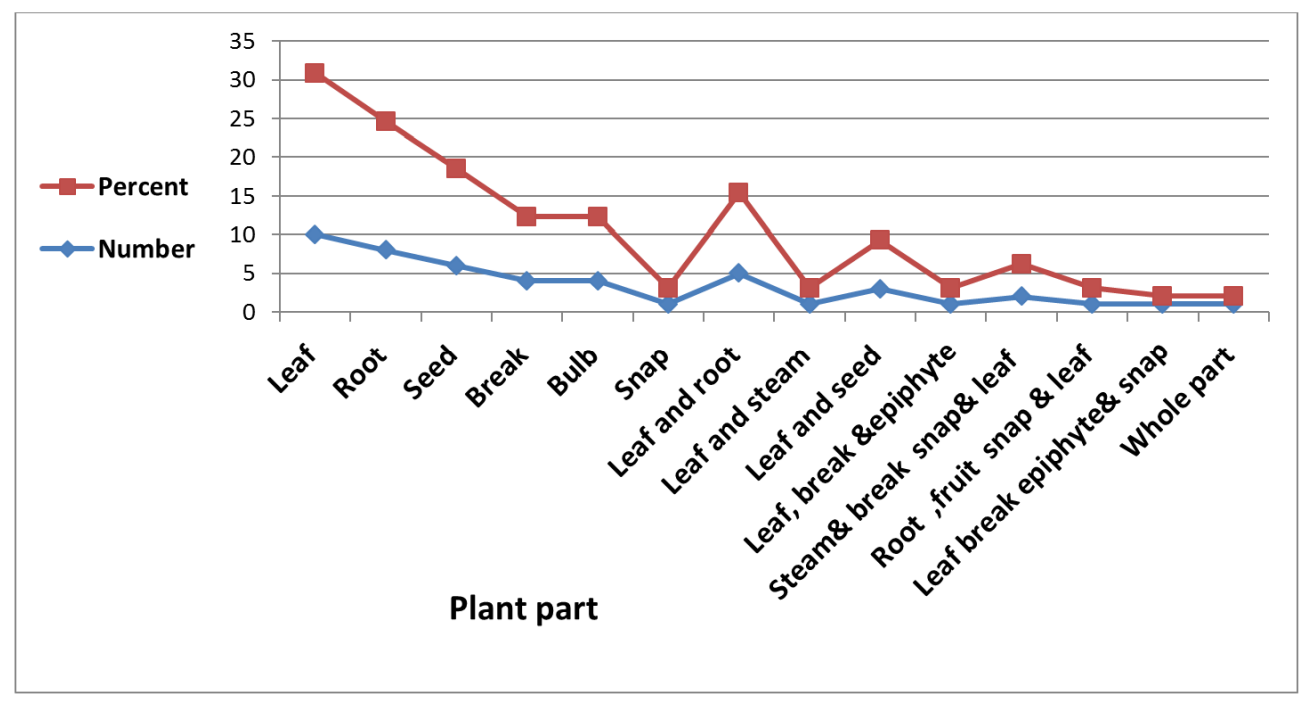

Figure 3. Percentage of medicinal plant parts used for human health treatment.

\subsection{Method of Preparation}

The preparations vary based on the type of disease treated and the actual site of the ailment. The principal methods of plant parts remedy preparation forms were reported to be through crushed, which accounts for $16(33.33 \%)$ followed by pounded $9(18.75 \%)$, squeezing $7(14.58 \%)$, chewing 5 $(10.42 \%)$, crashing and pounded $4(8.33 \%)$, cocking $3(6.25 \%)$, 
eating $1(2.08 \%)$, smoke/ burning $1(2.08 \%)$ crushed squeezed $1(2.08 \%)$, pounded and squeezed $1(2.08 \%)$ and pounding powder $1(2.08 \%)$ respectively. The most domina method of preparation is crushed. The result showed that the majority of remedies were prepared from single plant species and few are prepared from different, Solvents and additives which is a combination of medicinal plants, was used to treat a disease. In agreement with this study, similar researcher of medicinal plant species method of preparation is reported from different parts of the country by $[14,24,6,31]$.

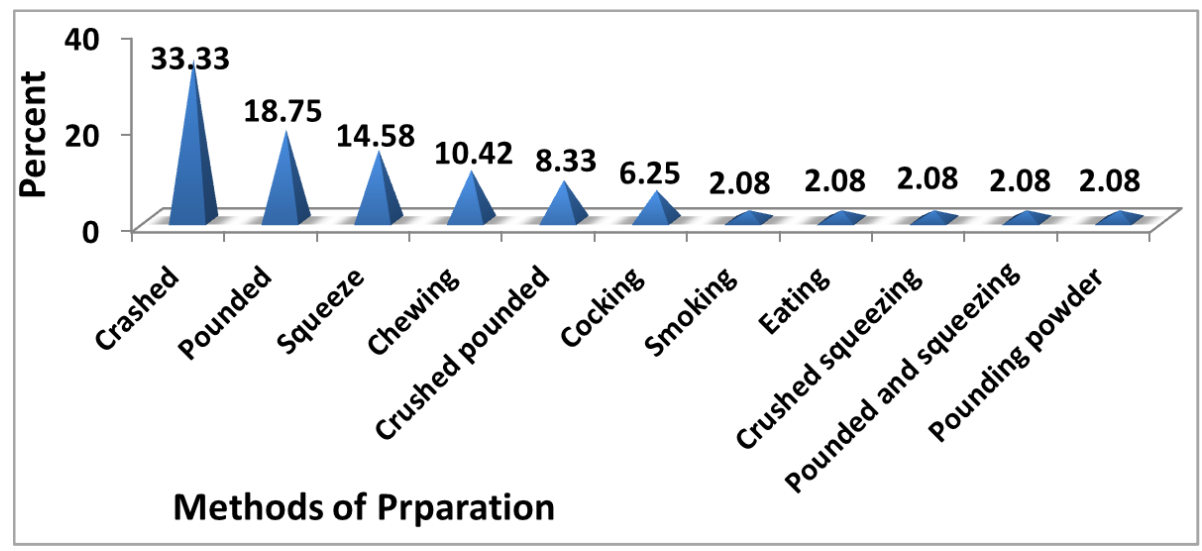

Figure 4. Method of preparation of medicinal plant used for human health treatment.

\subsection{Rout of Administration}

There are various routes of administration of traditional medicinal plants prepared products by the local community. The major routes of administration in the study area are oral, dermal, nasal, anal, tide; ear and fumigated People of the study area mostly administer traditional medicine orally. Oral accounts 25 (52.08\%) followed by dermal $6(16.67 \%)$, fumigated $4(8.33$ oral and dermal $2(4.17 \%)$ and others (Figure 8$)$. This fact that has been documented by different authors in the other part of Ethiopia [4, 13, 2, 1, 26, 21, 6, 23, 24].

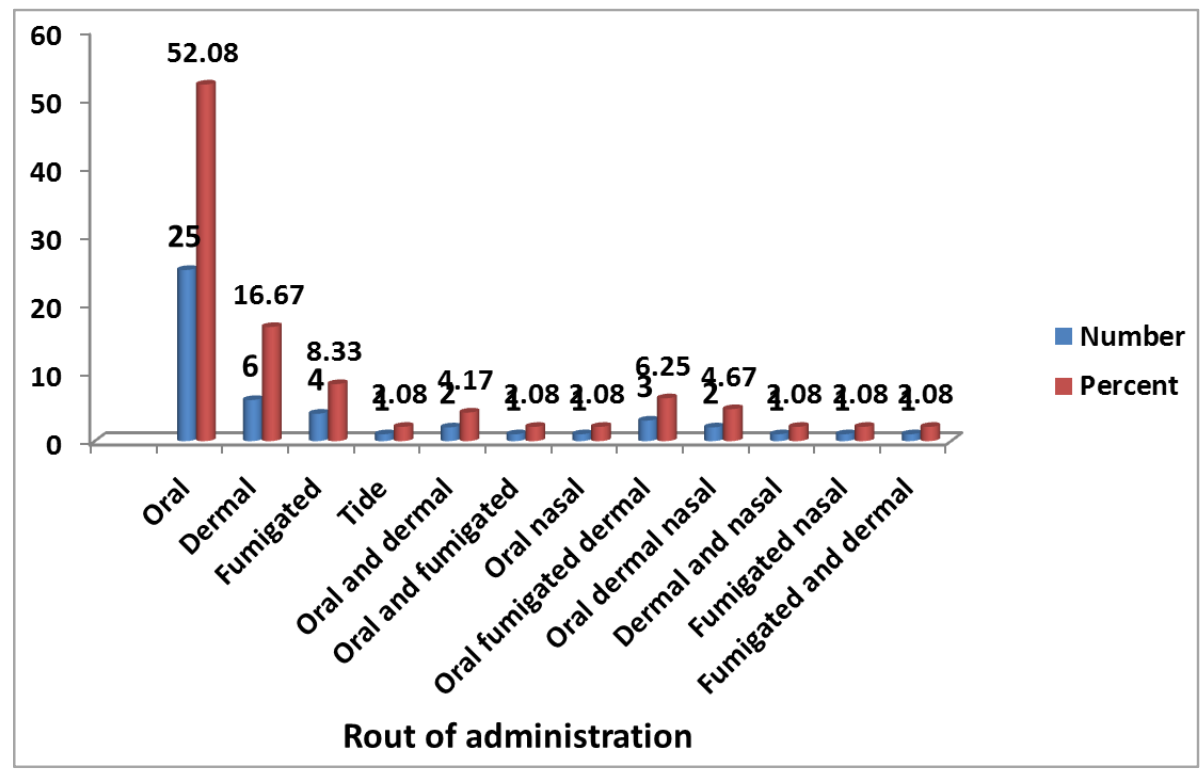

Figure 5. Rout of administration of medicinal plant used for human health treatment.

\subsection{Dosage of Medicinal Plants Used in Human Ailments}

People of the study area used various units of measurement and the duration of administration to determine the dosage. Local units such as finger length (e.g., for bark, root, stem,), different measuring materials (e.g., spoon, coffee cup, tea cup and glass cups) and numbers (e.g., for leaves, seeds, fruits, bulbs were used to estimate and fix the amount of medicine. But, these measurements are not accurate enough to determine the precise amount. For medicinal plants that are taken topically they do not have clear cut dosage [20, 29, 1, 28, 14], we have also discussed lack of precision and standardization as one drawback for the recognition of the traditional healthcare system. Although the most of remedies were reported to have no serious adverse effect vomiting and temporary inflammations. These could be attributed to low toxicity of the remedies preparation of medicinal plant species used by traditional healer in the study area. However, the toxicity of 
some medicinal plant and the potential to do harm is a common complaint among those who would like traditional medicine to be standardized. It is commonly believed that traditional practitioner either does not known the strength of their own medicine or does not brother to fit doses to the size or the body weight of the patient. However it is that some traditional healers do give different dosage and frequencies of application depending on age sex pregnancy and other condition or the medicinal itself on such difference. However, from the interview made during the study, it was found that there was disagreement among the healers concerning the dosage system used. For example, some informants suggested that two or three glass of the squeezed from Justicia schimperiana is used to treat, snake bit, malaria, stabbing pain and toxic substance while some suggested that only one glass is enough for the same problem. Still some others suggested that they apply the glass randomly without such measuring system or without mentioning a fixed by saying "squeezed of glass". Although the measurements used to determine the dosages are not standardized and doses given depend on the age, physical appearances and heath conditions; that is, children are given less dose than adults, physically strong individuals take more dose than weak individuals depending on the type of disease. Though such prescription difference was practiced, still the amount prescribed by healers for both children and adults might not conform to the standard prescriptions as in modern medical literature. The absence of any adverse effects of traditional medicines after administration were also more frequently mentioned by the traditional healers but some of the preparations were reported to have some adverse effects like diarrhea, headic, abdominal paine and vomiting. The traditional healers indicated that they use antidotes for the adverse effects of some traditional medicines like eating cooked teff flour and honey, drinking boiled coffee, "yedoro weat" milke <ergo> suger after taking the medicine. For instance, the use of Euphorbia abisanica for the treatment of gonorrhea, the sanp is collected mixed with "teff" powdered and backed and then eaten before any food for 3 days. During that diarrhea follows, as an antidote the local healers ask the patient to drunk boiled coffee.

In addition to the use of Jatropha curcas for the treatment of Rabbis, one seed are pounded, powdered, mixed with milk then the filtrate the solution is drunk. During that dihareha follows, as an antidote the local healers ask the patient to drunk borede and milk. In addition to the use of Niccotino tabacum for the treatment of snake bit, one leaf is pounded, powdered, mixed with water then the filtrate the solution is drunk. During that vomiting follows, as an antidote the local healers ask the patient to drink milk.

\subsection{Application}

The prepared traditional medicines are applied in a number of methods, drinking account the largest that account 12 $(25.00 \%)$, followed by smoking $10(20.83 \%)$, sniffing 7 (14.58\%), dropping $5(10.42 \%)$, painting 4 (8.33) swallowing 3 (6.25) eating 2 (4.17) put on 1 (2.08) tide 1 (2.08) washing accounts 2 (4.17) burshing 1 (2.08)\% (seen Figure 6). Internal ailments were commonly treated by making the patient drink herbal preparations; tooth infection were treated by crushing and put on the remedial plant part on the tooth surface; skin infections such as ringworm were treated by painting herbal preparations on an infected skin.

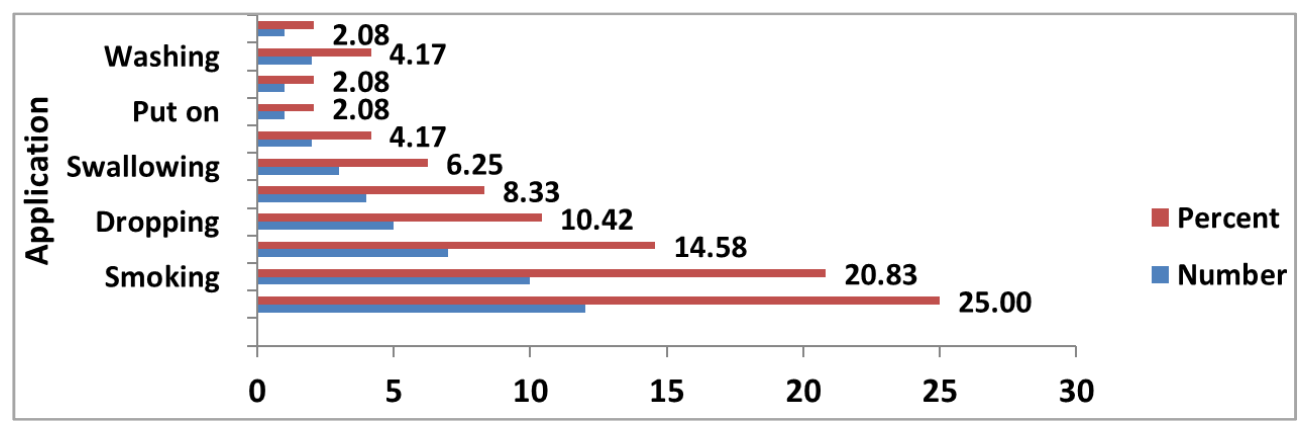

Figure 6. Application of medicinal plant used for human health treatment.

Sources and Transferring of Indigenous knowledge

Sources of Traditional knowledge practices.

The highest number of traditional medicinal plant knowledge gain from to be $45(45.4 \%)$ Father followed by 20 (2.02\%) form Mother and 15 (15.1\%) form Uncle 10 (10.1\%) from Brother, $8(8.08 \%)$ from Sister 6 (6.06) from Neighborhood and $5(5.05 \%)$ form Friend. The great majority of respondents $(90 \%)$ reported that most of their knowledge was received from their family members and friends secretly by oral. The secret practices of traditional medicines came from their ancestors. Within my finding similar studies are agreed by $[28,26,31,24$,$] .$

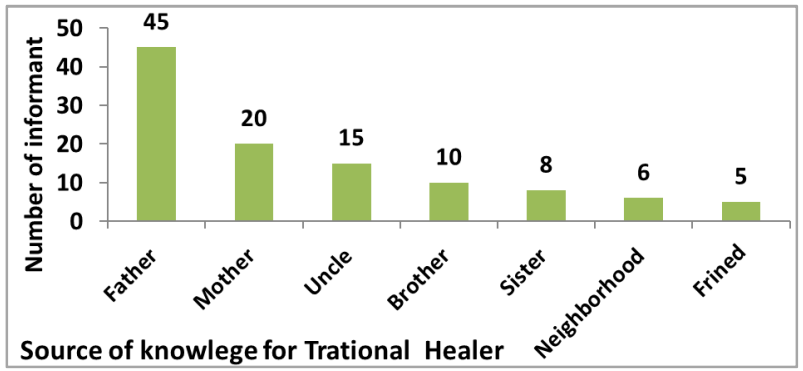

Figure 7. Sources of knowledge on the practice of traditional medicine. 


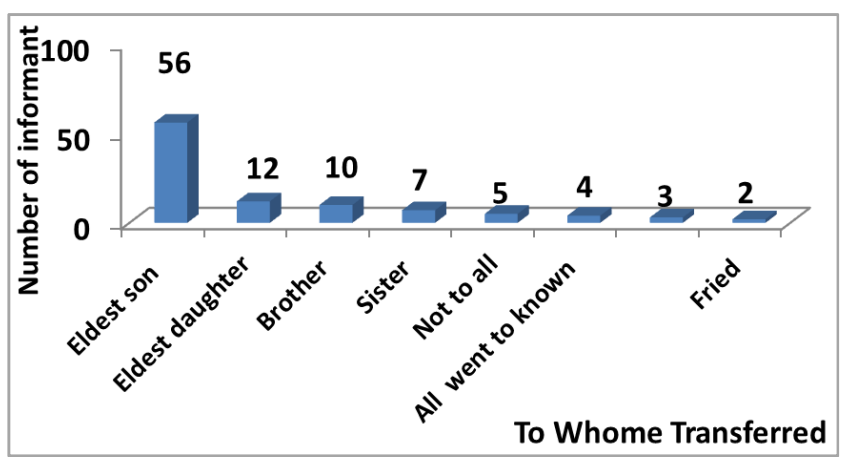

Figure 8. Transferring of knowledge of traditional medicinal plants.

\subsection{Transferring Knowledge of Traditional Medicinal Plants}

According to the survey, knowledge transfer of medicinal plants follows vertical transfer to the most selected family member orally with great secrecy. The findings of the study showed that as people become older and older their knowledge of traditional medicine becomes better and better. Most of the informants were elders that indicated the trend of transferring knowledge is usually at old age. The highest number for the ways of transferring knowledge on traditional medicinal plants by elder son who received 56 $(56.5 \%)$ votes followed by the elder daughter $12(12.1 \%)$, for the brother $10(10.1 \%)$ for the sister $7(7.07 \%)$ for the not to all $5(5.05 \%)$ for all went to known $4(4.04 \%)$ to all the member of my family $3(3.03 \%)$ and other to fried 2
$(2.02 \%)$ (Figure 7). Therefore most way of indigenous knowledge transfer in the study District was by word of mouth to a family member (especially to an elder son). Similar findings were reported for other communities in Ethiopia [26, 24, 31].

\section{Ranking of Most Important Medicinal Plants}

\subsection{Preference Ranking}

Preference ranking for eleven medicinal plants to treat snake biting (Table 6) made by ten informants showed that Bersema abyssinaca ranked first and hence is the most effective medicinal plant to cure snake biting. Myrsine melanophloeos, Nicotiana tabacum, Justicia schimperiana and Allium sativum. Are the $2^{\text {nd }}, 3^{\text {rd }}, 4^{\text {th }}$ and $5^{\text {th }}$ respectively.

\subsection{Direct Matrix Ranking}

Direct matrix ranking was performed to assess the relative importance each of the plant. The result of the direct matrix ranking showed that Cordia africana stood first in being the most multipurpose medicinal plant followed by Gardenia ternifolia, Eucalyptus globulus, Myrsine melanophloeos Croton macrostachyus Del. Acacia abyssinica, Ximenia caffra. sond, Bersema abyssinaca and Jatropha curcas was the least (Table 7).

Table 1. Preference ranking of eleven Selected Medicinal Plants based on the Degree of their Curative Power of snake bit as Perceived by Informant.

\begin{tabular}{|c|c|c|c|c|c|c|c|c|c|c|c|c|}
\hline \multirow{2}{*}{ Name of plants species } & \multicolumn{12}{|c|}{ Respondents (R1-R10) } \\
\hline & $\mathbf{R}_{1}$ & $\mathbf{R}_{\mathbf{2}}$ & $\mathbf{R}_{\mathbf{3}}$ & $\mathbf{R}_{\mathbf{4}}$ & $\mathbf{R}_{\mathbf{5}}$ & $\mathbf{R}_{\mathbf{6}}$ & $\mathbf{R}_{7}$ & $\mathbf{R}_{8}$ & $\mathbf{R}_{\mathbf{9}}$ & $\mathbf{R}_{\mathbf{1 0}}$ & Total & Rank \\
\hline Allium sativum L. & 4 & 3 & 5 & 3 & 4 & 5 & 1 & 5 & 5 & 3 & 38 & $5^{\text {th }}$ \\
\hline Carduus englariaum Sch. Bip. Ex A. Rich. & 2 & 3 & 1 & 1 & 2 & 3 & 4 & 3 & 3 & 5 & 27 & $9^{\text {th }}$ \\
\hline Carissa spinarum $\mathrm{L}$. & 2 & 5 & 5 & 4 & 5 & 5 & 2 & 5 & 3 & 1 & 37 & $6^{\text {th }}$ \\
\hline Justicia schimperiana (Hochst. ex Nees) T. Anders. & 4 & 5 & 5 & 2 & 5 & 4 & 5 & 4 & 2 & 3 & 39 & $4^{\text {th }}$ \\
\hline Lagenaria siceraria (Mol.) Standl. & 4 & 4 & 0 & 1 & 4 & 3 & 2 & 2 & 1 & 3 & 24 & $11^{\text {th }}$ \\
\hline Paveonia urenscav & 5 & 2 & 5 & 3 & 2 & 4 & 5 & 4 & 1 & 5 & 36 & $6^{\text {th }}$ \\
\hline Stereospermum kunthianum & 4 & 2 & 2 & 4 & 5 & 2 & 2 & 5 & 5 & 4 & 30 & $9^{\text {th }}$ \\
\hline Bersema abyssinaca & 5 & 5 & 5 & 4 & 5 & 5 & 4 & 4 & 5 & 5 & 47 & $1^{\mathrm{st}}$ \\
\hline Dicrocephale latifolia & 5 & 4 & 2 & 2 & 3 & 2 & 3 & 3 & 3 & 4 & 31 & $8^{\text {th }}$ \\
\hline Myrsine melanophloeos & 5 & 4 & 4 & 5 & 5 & 5 & 4 & 5 & 5 & 4 & 46 & $2^{\text {nd }}$ \\
\hline
\end{tabular}

Table 2. Direct matrix ranking for seven specie and main use in study area.

\begin{tabular}{|c|c|c|c|c|c|c|c|c|c|}
\hline \multirow{2}{*}{ NamePlant species } & \multicolumn{9}{|c|}{ Use categories } \\
\hline & Charcoal & Construction & Medicine & Food & Firewood & Fencing & Furniture & Total & Rank \\
\hline Jatropha curcas & 0 & 0 & 4 & 0 & 3 & 5 & 1 & 13 & $9^{\text {th }}$ \\
\hline Ximenia caffra. sond & 0 & 2 & 5 & 5 & 5 & 3 & 2 & 22 & $7^{\text {th }}$ \\
\hline Cordia africana Lam. & 5 & 5 & 5 & 4 & 5 & 3 & 5 & 32 & $1^{\text {st }}$ \\
\hline Croton macrostachyus Del. & 5 & 5 & 5 & 0 & 4 & 4 & 2 & 24 & $5^{\text {th }}$ \\
\hline Acacia abyssinica & 5 & 5 & 3 & 0 & 4 & 3 & 3 & 23 & $6^{\text {th }}$ \\
\hline Eucalyptus globulus & 5 & 5 & 3 & 0 & 5 & 5 & 5 & 28 & $3^{\text {rd }}$ \\
\hline Myrsine melanophloeos & 5 & 5 & 5 & 0 & 5 & 2 & 3 & 25 & $4^{\text {th }}$ \\
\hline Bersema abyssinaca & 1 & 2 & 5 & 0 & 3 & 3 & 1 & 15 & $8^{\text {th }}$ \\
\hline Gardenia ternifolia & 2 & 3 & 5 & 3 & 4 & 3 & 5 & 30 & $2^{\text {nd }}$ \\
\hline Total & 33 & 30 & 40 & 12 & 47 & 31 & 23 & & \\
\hline Rank & $3^{\text {rd }}$ & $5^{\text {th }}$ & $2^{\text {nd }}$ & $7^{\text {th }}$ & $1^{\mathrm{st}}$ & $4^{\text {th }}$ & $6^{\text {th }}$ & & \\
\hline
\end{tabular}




\subsection{Paired Comparison}

A paired comparison made to determine the most preferred medicinal plants among the 9 species that were used to treat eye vile in the study area, the responses of ten key informants, showed that Ranked Withania somnifera first followed by Gardenia ternifolia. (Table 3). Therefore, this result indicated that Withania somnifera. is the most preferred while. Clausena anisata is the least favored over the other plant species cited in treating eye vile.

Table 3. Paired comparisons of five medicinal plant species used to treat fibril illness.

\begin{tabular}{|c|c|c|c|c|c|c|c|c|c|c|c|c|}
\hline \multirow{2}{*}{ Name of plants species } & \multicolumn{12}{|c|}{ Respondents (R1-R10) } \\
\hline & $\mathbf{R}_{1}$ & $\mathbf{R}_{2}$ & $\mathbf{R}_{3}$ & $\mathbf{R}_{4}$ & $\mathbf{R}_{\mathbf{5}}$ & $\mathbf{R}_{6}$ & $\mathbf{R}_{7}$ & $\mathbf{R}_{8}$ & $\mathbf{R}_{\mathbf{9}}$ & $\mathbf{R}_{10}$ & Total & Rank \\
\hline Gardenia ternifolia & 1 & 4 & 3 & 0 & 1 & 1 & 2 & 4 & 5 & 4 & 35 & $2^{\text {nd }}$ \\
\hline Allium sativum L. & 2 & 2 & 1 & 4 & 3 & 2 & 4 & 3 & 2 & 5 & 28 & $5^{\text {th }}$ \\
\hline Croton macrostachyus Del & 5 & 5 & 1 & 4 & 2 & 2 & 1 & 0 & 1 & 4 & 25 & $8^{\text {th }}$ \\
\hline Vernonia amygdalina Del. & 1 & 0 & 2 & 4 & 3 & 1 & 4 & 1 & 5 & 1 & 27 & $6^{\text {th }}$ \\
\hline Secuidaca longepedunculta & 4 & 1 & 0 & 4 & 1 & 2 & 1 & 4 & 5 & 4 & 26 & $7^{\text {th }}$ \\
\hline Clausena anisata & 4 & 4 & 1 & 0 & 4 & 1 & 4 & 3 & 1 & 0 & 22 & $9^{\text {th }}$ \\
\hline Capparis tomentosa & 1 & 2 & 4 & 2 & 4 & 2 & 4 & 4 & 3 & 5 & 31 & $3^{\text {rd }}$ \\
\hline Withania somnifera & 4 & 2 & 4 & 4 & 5 & 1 & 5 & 4 & 4 & 5 & 38 & $1^{\mathrm{st}}$ \\
\hline
\end{tabular}

\section{Threatened and Factor Threatening Medicinal Plants in Dibati Woreda}

\subsection{Threatened Medicinal Plant in the Study Area}

The ranking of 9 medicinal plants based on the degree of threats was conducted using 10 key informantsThe results (Table 4) indicated that is Asparagus africanus and Myrsine melanophloeos the most threatened followed by Withania somnifera (L.) and Bersema abyssinaca and the least threatened one is Glinus lotoides $L$.

Table 4. Ranking of threatened plants.

\begin{tabular}{|c|c|c|c|c|c|c|c|c|c|c|c|c|}
\hline \multirow{2}{*}{ Name of plants species } & \multicolumn{12}{|c|}{ Respondents (R1-R10) } \\
\hline & $\mathbf{R}_{1}$ & $\mathbf{R}_{2}$ & $\mathbf{R}_{3}$ & $\mathbf{R}_{4}$ & $\mathbf{R}_{\mathbf{5}}$ & $\mathbf{R}_{6}$ & $\mathbf{R}_{7}$ & $\mathbf{R}_{8}$ & $\mathbf{R}_{9}$ & $\mathbf{R}_{10}$ & Total & Rank \\
\hline Myrsine melanophloeos & 1 & 4 & 3 & 0 & 1 & 1 & 2 & 4 & 5 & 4 & 35 & $2^{\text {nd }}$ \\
\hline Bersema abyssinaca & 4 & 1 & 2 & 2 & 4 & 5 & 5 & 4 & 2 & 1 & 30 & $4^{\text {th }}$ \\
\hline Paveonia urenscav & 2 & 2 & 1 & 4 & 3 & 2 & 4 & 3 & 2 & 5 & 28 & $5^{\text {th }}$ \\
\hline Oncoba spinosa Forssk. & 5 & 5 & 1 & 4 & 2 & 2 & 1 & 0 & 1 & 4 & 25 & $8^{\text {th }}$ \\
\hline Momoridica foetida. schum & 1 & 0 & 2 & 4 & 3 & 1 & 4 & 1 & 5 & 1 & 27 & $6^{\text {th }}$ \\
\hline Kalancheo petitiana A. Rich, & 4 & 1 & 0 & 4 & 1 & 2 & 1 & 4 & 5 & 4 & 26 & $7^{\text {th }}$ \\
\hline Glinus lotoides L. & 4 & 4 & 1 & 0 & 4 & 1 & 4 & 3 & 1 & 0 & 22 & $9^{\text {th }}$ \\
\hline Withania somnifera (L.) & 1 & 2 & 4 & 2 & 4 & 2 & 4 & 4 & 3 & 5 & 31 & $3^{\text {rd }}$ \\
\hline Asparagus africanus & 4 & 2 & 4 & 4 & 5 & 1 & 5 & 4 & 4 & 5 & 38 & $1^{\mathrm{st}}$ \\
\hline
\end{tabular}

\subsection{Factors Threatening Medicinal Plants in the Study Area}

The major reported threats of medicinal plants in the current study areas are agricultural expansion, including clearance of the major habitats of the species, and low attention of the local communities in conserving and protecting the species. However, there were reportedly indirect conservation activities of the species. These included the planting of the species for indirect uses such as aesthetics, fence, food, shade, spice, fuel wood, and source of income. Informants ranked agricultural expansion, fire wood and population pressure as the most serious threat to the medicinal plants followed by medicinal purpose and charcoal collection is lower levels of threats by the other factors (Table 5). Similar study [32, $16,2,26,31]$. This showed that, there are different threats in medicinal plants such as agricultural expansion fire wood collection and others.

The agricultural expansion and deforestation was the major medicinal plant treats. The finding was in line with other findings [19]. This might be due to continuous agricultural expansions, deforestation and draught in addition to lack attention towards the medicinal plants. The plants are disappeared because of rapid socioeconomic, environmental and technological changes and as a result of the loss of cultural heritage under the guise of civilization. 
Table 5. Ranking of threats to medicinal plants.

\begin{tabular}{|c|c|c|c|c|c|c|c|c|c|c|c|c|}
\hline \multirow{2}{*}{ Name of plants species } & \multicolumn{12}{|c|}{ Respondents (R1-R10) } \\
\hline & $\mathbf{R}_{1}$ & $\mathbf{R}_{2}$ & $\mathbf{R}_{3}$ & $\mathbf{R}_{4}$ & $\mathbf{R}_{5}$ & $\mathbf{R}_{6}$ & $\mathbf{R}_{7}$ & $\mathbf{R}_{8}$ & $\mathbf{R}_{\mathbf{9}}$ & $\mathbf{R}_{10}$ & Total & Rank \\
\hline Fire wood & 4 & 5 & 5 & 4 & 3 & 4 & 3 & 5 & 2 & 5 & 40 & $2^{\text {nd }}$ \\
\hline Medicinal purpose & 2 & 1 & 2 & 1 & 2 & 2 & 1 & 2 & 2 & 1 & 16 & $8^{\text {th }}$. \\
\hline Charcoal Making & 4 & 2 & 3 & 2 & 3 & 1 & 3 & 4 & 1 & 3 & 23 & $7^{\text {th }}$ \\
\hline Household tool construction & 4 & 5 & 5 & 3 & 1 & 2 & 4 & 4 & 2 & 3 & 33 & $6^{\text {th }}$ \\
\hline Over grazing & 3 & 4 & 4 & 2 & 5 & 5 & 4 & 3 & 2 & 3 & 35 & $4^{\text {th }}$ \\
\hline Agriculture expansion & 5 & 4 & 5 & 5 & 5 & 4 & 4 & 5 & 5 & 5 & 47 & $1^{\mathrm{st}}$ \\
\hline Urbanization & 3 & 2 & 4 & 5 & 4 & 3 & 2 & 2 & 5 & 4 & 34 & $5^{\text {th }}$ \\
\hline population pressure & 5 & 2 & 3 & 4 & 5 & 5 & 3 & 3 & 4 & 5 & 39 & $3^{\text {rd }}$ \\
\hline
\end{tabular}

\subsection{Management and Conservation of Medicinal Plants}

As a result many medicinal plants are under serious threats. So the local people should be conserve medicinal plant in-suit and ex-suit management style. Those manes that forty eight medicinal plants that are collected in the wild by conserve in-suit conservation method and the reaming seventeen medicinal plants that conserve by ex-suit conservation method. According to the informant information generally, there are some conservation measures that have been under taken around the world aimed at protecting threatened medicinal plant species from further destruction by create awareness for the user local people for the use and management of medicinal plant in study area.

Some authors clarify that home gardens can be refuge for wild species that are threatened in the wild by deforestation and environmental changes. Concerning this [33]. Reported that home gardens are being used as informal experimentation plots for new varieties and exotic species. Informants also reported that the healers know time and processes of gathering, and storing medicinal plants. It is once a year that some medicinal plants are collected and preserved. Lepidium sativum, Cucuribita pepo, Jatropha curcas and Ocimim basilicum seed, leaf, fruit or root are harvested, dried and preserved in roof corners or outside house, and dried parts are powdered and stored in different containers like pots, bottles or tied with clothes and used when needed. The study indicated that many of the informants who have knowledge on traditional medicine usage give priority to the immediate use of the medicinal plants than to its sustainable future uses, as a result their harvesting style is destructive. However, some plants has protected for their spiritual and cultural purposes. Thus, these places are good sites for the protection of the medicinal plants since cutting and harvesting are not allowed in such particular areas. This was indicated that a good practice for the conservation of medicinal plants through cultivation [26].

\section{Informant Consensus Factor (ICF)}

All cited human and livestock diseases were categorized into 7 categories: namely, Sense organs related diseases, Animal and insect biting related disease, digestive system related disease, Reproductive system related diseases, Cultural related disease, Respiratory disease related diseases, intestinal and parasitic infection related diseases, and derma related disease, These diseases are categorized based on nature of disease, conditions that cause, place of attack, symptoms and sign of disease (Table 6). Disease categories with relatively higher ICF values were: intestinal and parasitic infection related diseases (0.89), derma related diseases (0.87) Sense organs related diseases (0.83), Cultural related diseases (0.73). This may indicate the common occurrence of these diseases so that more number of people exchanging information and agree on plant species that can be used to treat these diseases than the rest. The medicinal plants that are presumed to be effective in treating a certain disease have higher ICF values. On the other hand, the rest of disease categories had ICF value of lower suggesting that these diseases are either rare in the study area or are treated only by the healers with little information passed to other general public.

Table 6. Informant consensus factor (ICF).

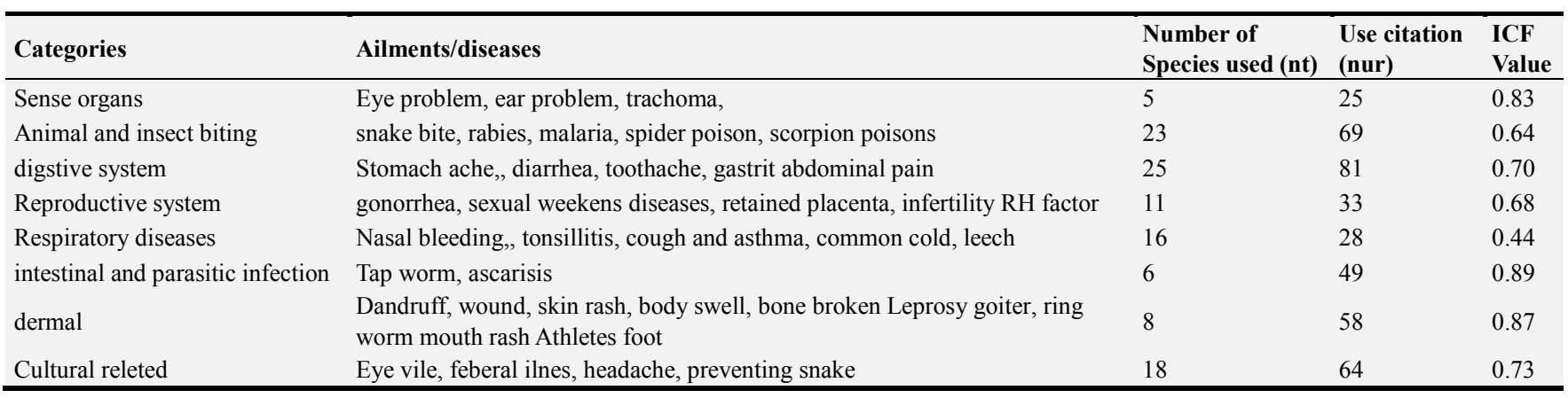




\subsection{Fidelity Level Index (FLI)}

Fidelity level (FL) quantifies the importance of a species for a given purpose. Hence, fidelity level values were calculated for commonly used individual medicinal plants against the following ailments: Justicia schimperiana (against snake biting and Rabbis) Asparagus africanaus (against retained of placenta) Croton macrostachyus (against eye vile), Stereospermum kunthianum (Tonsil, scorpion biting), Momoridica foetida. schum (against Bleeding during delivery) Euphorbia abyssinica (against Hemorrhoid, gonorrhea) Paveonia urenscav (against Rheumatic, tooth ache) and Protulaca sp. (against Gastritis). In the fact that these medicinal plants had the highest FL values which could be an indication of their good healing potential (Table 7).

Table 7. The relative healing potential of individual medicinal plants used against human or livestock ailments.

\begin{tabular}{|c|c|c|c|c|c|c|}
\hline No & Medicinal plants species & Aliments treated & IP & IU & FLI (\%) & Rank \\
\hline 1 & Croton macrostachyus & Evile eye & 52 & 58 & 89.6 & $3^{\text {th }}$ \\
\hline 2 & Justicia schimperiana (Hochst. ex Nees) T. Anders. & Snake biting, rabbis & 47 & 47 & 100 & $1^{\mathrm{st}}$ \\
\hline 3 & Asparagus africanus (kunth) Baker & Retained placenta & 38 & 41 & 92.6 & $2^{\text {rd }}$ \\
\hline 4 & Stereospermum kunthianum Cham. & Tonsil, scorpion biting & 31 & 35 & 88.57 & $4^{\text {th }}$ \\
\hline 5 & Euphorbia abyssinica J. F Gmel & Hemorrhoid, gonorrhea & 29 & 37 & 78.38 & $6^{\text {th }}$ \\
\hline 6 & Momoridica foetida. schum & Bleeding during delivery & 26 & 31 & 83.8 & $5^{\text {th }}$ \\
\hline 7 & Protulaca sp. & Gastritis & 21 & 29 & 72.4 & $7^{\text {th }}$ \\
\hline 8 & Paveonia urenscav & Rheumatic, tooth ache & 19 & 25 & 76.0 & $8^{\text {th }}$ \\
\hline
\end{tabular}

\subsection{Medicinal Use Value}

While some plant species are known to treat a single ailment, some others may be used for multiple of health problems. Medicinal use value is a quantitative method that demonstrates the relative importance of species known locally [33]. Some species that were cited for more than one ailment were selected and their use value was calculated. Results of use value computation for these species showed that Croton macrostachyus and had the Carissa spinarum highest use value (Table 8). This suggests that these species are used to treat many ailments. For example, Croton macrostachyus was reported to treat ailments such amoeba, evil eye, febrile illness, wound, prevent snake, skin infection and malaria. On the other hand was Carissa spinarum L. reported to treat snake biting, ascarises, malaria, gonorrhea, Amoeba, febrile illness and diarrhea. Justicia schimperiana was reported to treat aliments such as snak biting, anti-toxic stabbing malaria, rabbis and typhoid's. Stereospermum kunthianum was reported to treat aliments such as scropion biting, retained plasta, gasterite, tosile, snake biting and stomachache.

Table 8. Use Value of Certain Medicinal Plants in Study Area.

\begin{tabular}{llll}
\hline Plant species & Use citation (U) & Number of informants (n) & Use value (Uv) \\
\hline Croton macrostachyus & 7 & 23 & 0.35 \\
Carissa spinarum L. & 7 & 19 & 0.37 \\
Stereospermum kunthianum Cham. & 6 & 12 & 0.50 \\
Justicia schimperiana (Hochst. ex Nees) T. Anders & 6 & 14 & 0.43 \\
Vernonia amygdalina Del. & 5 & 12 & 0.42 \\
Combretum collinum & 5 & 13 & 0.38 \\
Paveonia urenscav & 5 & 15 & 0.33 \\
Cordia africana Lam. & 5 & 23 & 0.22 \\
Solanu nigrum & 4 & 11 & 0.36 \\
Kalancheo petitiana A. Rich & 4 & 9 & 0.44 \\
Gardenia lutea Fresen. & 4 & 12 & 0.33 \\
Allium sativum L. & 3 & 7 & 0.43 \\
Clutia abyssinica Jaub. and Spach & 3 & 5 & 0.60 \\
Coffea arabica L. & 3 & 25 & 0.12 \\
Ximenia caffra. sond & 3 & 8 & 0.38 \\
Nicotiana tabacum L. & 3 & 7 & 0.43 \\
Ruta chalepensis L. & 3 & 19 & 0.16 \\
Eucalyptus globulus. Labil. & 3 & 20 & 0.15 \\
Zingiber officinale Roscoe, & 3 & 15 & 0.20 \\
Clematis hirsuta perr and Guill & 3 & 12 & 0.25 \\
Euphorbia abyssinica J. F Gmel & 3 & 4 & 0.75 \\
Linum usitatissimum L. & 3 & 11 & 0.27 \\
Oncoba spinosa Forssk. & 3 & 9 & 0.33 \\
\hline
\end{tabular}




\section{Conclusion}

A study on medicinal plant utilization in area revealed that the shinasha communities commonly use medicinal plants for maintaining their primary healthcare. The study resulted in documenting 57 medicinal plants species 46 genera 28 family where Fabaceae is the leading family with the highest proportion of medicinal plants. The majorities of these medicinal plant species were obtained and collected 36 from wild, 12 from home garden. Analysis of growth forms of these medicinal plants that herbs constitute the largest category 19 (39.5\%) followed by tree 12 (25.00\%) shrub 16 (24.61\%) plant species. Herbal remedies are prepared from fresh materials 45 $(62.23 \%)$ and dried plant materials $8(12.30 \%)$ and in both condation $18(18.46 \%)$. In the study area, 72 ailments were reported ( 57 for human) which are being treated by traditional medicinal plants of the area. Leaves were the most frequently used plant parts followed by roots for preparation of human and livestock remedies. Most of the medicinal plants are administered orally (52.08\%) and followed dermal (1667). The most widely used method of preparation was crashed $(33.33 \%)$, Pounding $(18.75 \%)$, of the different medicinal plant parts. They have a wide knowledge in using plants for various purposes such as for medicine, food, household utensils, fodder, fuel, construction, etc. This knowledge is transferred from elders to youngsters entirely through oral traditions and personal experiences. The major threats to medicinal plants and the associated knowledge in the study area are mainly agricultural expansion, firewood collection, population pressure, over gaze ring, urbanization, household tool construction, charcoal production and medicinal purpose. Therefore, use and management system awareness rising should be made among the healers so as to avoid erosion of the indigenous knowledge and to ensure its sustainable use.

\section{Conflicts of Interest}

The authors declare that they have no competing interests.

\section{Acknowledgements}

We would like to express our sincere appreciation to dibati worda admistration office for the financial support during this study. We are thankful to the local communities of the district, Meteke Zone Dibati Worda Modermo, Bechati, Legbuna, Gireze and Zegeh Kebele (Bari Villige Peoples) for their providing the necessary information about use of medicial plant on the study area during data collection. The people of Dibati District including the local authorities were also acknowledged for their positive response, sharing their valuable knowledge and times as well as for their tremendous generosity and hospitality. Dr. Tena Regassa deserved our heartfelt gratitude for their help in identification of plant specimens. Finally, our sincere appreciation goes to $\mathrm{Mr}$. Gadissa who prepared the local map of the study District.

\section{References}

[1] Abiyu Enyew, Zemede A, Ensermu K, Raja N (2014). Ethnobotanical Study of Traditional Medicinal Plants in and Around Fiche District, Central Ethiopia. Current Research Journal of Biological Sciences 6 (4): 154-167. Addis Ababa, Ethiopia, Uppsala Sweden 2009; 8: 1-7.

[2] Assegid Assefa and Tesfaye Abebe. (2014). Ethnobotanical Study of Wild Medicinal Trees and Shrubs in Benna Tsemay District, Southern Ethiopia. Journal of Science \& Development 2 (1) 17.

[3] Ayeni. E and Basiri B. (2018). Ethnoveterinary Survey of Plants used in Treating Livestock among the Fulani people of Girei, Adamawa State, Nigeria. WNOFNS: 53-66 EISSN 2543-5426.

[4] Balcha Abera (2014). Medicinal plants used in traditional medicine by Oromo people, Ghimbi District, Southwest Ethiopia. Journal of Ethnobiology and Ethnomedicine; 10 (40): 1-15.

[5] Bayafers Tamene (2000). A Floristic Analysis and Ethnobotanical Study of the Semi- Wet land of Cheffa Area, South Wello, Ethiopia. Agriculture and Healthcare: ISSN 2224-3208 (Paper) ISSN 2225-093 Vol. 5, No. 1.

[6] Bizuneh Woldeab, Reta Regassa, Tibebu Alemu, and Moa Megersa (2018). Medicinal Plants Used for Treatment of Diarrhoeal Related Diseases in Ethiopia. Evidence-Based Complementary and Alternative Medicine Volume Article ID4630371, 20 pages https://doi.org/10.1155/2018/4630371

[7] Cotton, C. M., 1996. Ethnobotany: Principles and Applications. John Willey and Sons LTD. Chichester, UK, pp. 424.

[8] Endalew Amenu (2007). Use and Management of Medicinal Plants by indigenous People of Ejaji Area (Chelya Wereda) West Shewa, Ethiopia: An Ethnobotanical Approach, M.Sc Thesis. Addis Ababa Ethiopia.

[9] Endeshaw Bekele (2007): study on actual situation of mechanical plants in Ethiopia prepared for Japan association for international collaboration of agriculature and forestry.

[10] Debela Hunde. (2001). Use and Management of Traditional MedicinalPlants by Indigenous People of Bosat Woreda, Wolenchiti area: An ethnobotanical approach. M.Sc. Thesis, Addis Ababa, Ethiopia.

[11] Fisseha Mesfin (2007). An Ethnobotanical Study of Medicinal Plants in Wonago Wereda, SNNPR, Ethiopia, M.Sc. Thesis. Addis Ababa University, Addis Ababa. Ethiopia.

[12] Friedman, J. Yaniu, Z., Dafni, A. and Palewitch, D. (1986). A Preliminary Classification of the Haling Potential of Medicinal Plants, Based on the Rational Analysis of Ethnopharmacolgical Survey Among Bedouins in Negue Desert, Israel. Journal of Ethnophamacology 16: 275-2.

[13] Getnet Chokole, Zemede A, Ensermu K (2015). Ethnobotanical study of medicinal plants in the environs of Tara-gedam and Amba remnant forests of Libo Kemkem District, northwest Ethiopia. Journal of Ethnobiology and Ethnomedicine. 2015; 11 (4): 1-38. 
[14] Getnet Chekol (2017). Ethnobotanical study of medicinal plants used against human ailments in Gubalafto District, Northern Ethiopia. Journal of Ethnobiology and Ethnomedicine. 13: 55.

[15] Gidey Yirga (2010). Use of traditional medicinal plants by indigenous people in Mekele town, capital city of Tigray regional state of Ethiopia, Journal of Medicinal Plants Research 4: 25-50.

[16] Kebu Balemie, Ensermu Kelbessa and Zemede Asfaw., (2004). Indigenous medicinal plant utilization, management and threats in Fentalle area, Eastern Shewa, Ethiopia. Ethiopian Journal Biological Science, 3: 37-58.

[17] Luiz. R. Saldanha. G., Reinaldo, F., Paiva deA. (2005). Knowledge and use of medicinal plants by local specialist in a region of Atlantic Forest in the state of Pernambuco (North eastern Brazil).

[18] Martine G (1995). Ethnobotany: A method of manual Chopman and Hall London UK. Grat Britain University Press e Cambridg press p 267. May 1998, IBCR, Addis Ababa, Ethiopia.

[19] Mirutse Giday, Tilahun Teklehaymanot, Abebe Animut, and Yalemtsehay Mekonn (2007). Medicinal plants of the Shinasha, Agew-awi and Amhara peoples in northwest Ethiopia. Journal of Ethnopharmacology 110: 516-525.

[20] Moa Megersa (2010) Ethnobotanical Study of Medicinal Plants in Wayu Tuka Wereda, East Wollega Zone of Oromia Region,. MSC Thesis Addis Ababa, Ethioipa.

[21] Mulugeta Kebebew (2016). Knowledge of medicinal plants used in and around Fincha'a Town, Western Ethiopia. Journal of Pharmacognosy and Phytochemistry; 5 (6): 110-114.

[22] Nemarundwe, N. and Richards, M. (2002). Participatory methods for exploring livelihood Values derived from forests: potential and limitations. London. Pp. 168-198.

[23] Nigatu Tuasha, Beyene Petros and Zemede Asfaw (2018). Medicinal plants used by traditional healers to treat malignancies and other human ailments in Dalle District, Sidama Zone, Ethiopia. Journal of Ethnobiology and Ethnomedicine: 14: 15-22.

[24] Nigussie Amsalu, Yilkal Bezie, Mulugeta Fentahun, Addisu Alemayehu, and Gashaw Amsalu (2018). Use and
Conservation of Medicinal Plants by Indigenous People of Gozamin Wereda, East Gojjam Zone of Amhara Region, Ethiopia: Article ID 2973513, 23 pages https://doi.org/10.1155/2018/2973513

[25] Njau, A. E., 2001. An Ethnobotanical study of Medicinal Plants used by the Maasai People of Manayara, Arusha, Tanzania. M.Sc. Thesis. Addis Ababa, Ethiopia.

[26] Tadesse Birhanu, Dereje Abera and Eyasu Ejeta (2015). Ethnobotanical Study of Medicinal Plants in Selected Horro Gudurru Woredas, Western Ethiopia., Journal of Biology, Agriculture and Healthcare: ISSN 2224-3208 (Paper) ISSN 2225-093X (Online) Vol. 5, No. 1.

[27] Tafesse Mesfine and Mekonnen Lemma (2001), the role of traditional veterinary Herbal medicinal and its constraints in the animal health care system in Ethiopia, Addis Ababa Ethiopia.

[28] Tena Regasa, (2015). Vascular plant diversity and ethnobotanical study of medicinal and wild edible plants in Jibat, Gedo and Chilimo forests, West Shewa Zone of Oromia Region, Ethiopia, PhD Dissertation, Addis Ababa, Ethiopia.

[29] Tolosssa. k, Debela. E Athanasiadous. S, Tolora. A., Ganga. G, Houdijk, J (2013) ethno-medicinal study of plant used for treateament of human and livestock aliment by traditional healer in south omo, southern Ethiopia. Ethio biol. ehtnomed. 9: 32 .

[30] Yamane T (1967) Statics, an Introduction Analysis, 2nd Ed., New York: Harper and Row.

[31] Yihenew Simegniew Birhan, Sintayehu Leshe Kitaw, Yihalem Abebe Alemayehu, Nakachew Minuye Mengesha (2018), Ethnobotanical study of medicinal plants used to treat human diseases in Enarj Enawga District, East Gojjam Zone, Amhara Region, Ethiopia. SM J Med Plant Stud.; 2 (1): 1006.

[32] Zerhiun W, Mesfin T (1990). The Status of the Vegetation in the Lake region of the Rift Valley of Ethiopia and Possibilities of its Recovery. SINET: Eth. J. Sci., 392: 97-120.

[33] Zemede Asfaw (2001). The role of home gardens in production and conservation of medicinal plants. In: Conservation and Sustainable Use of Medicinal Plants in Ethiopia, Proceeding of The National Work Shop on Biodiversity and Sustainable use of Medicinal Plants In Ethiopia, 2. 